\title{
Leadership styles and associated personality traits: Support for the conceptualisation of transactional and transformational leadership
}

\author{
René van Eeden \\ Department of Psychology, University of South Africa, P O Box 392, Pretoria, 0003, \\ South Africa \\ veeder@unisa.ac.za

\section{Frans Cilliers} \\ Department of Industrial and Organisational Psychology, University of South Africa, \\ Pretoria, South Africa
}

\section{Vasi van Deventer}

Department of Psychology, University of South Africa, Pretoria, South Africa

The full range model of leadership includes laissez-faire behaviour, transactional leadership, and transformational leadership. The model conceptualises leadership in terms of the behaviours associated with various styles and this conceptualisation has been empirically supported. In this article the personality traits of managers exercising different leadership styles are explained in terms of, and add to, the description of these styles. Members of a management team were assessed in terms of their preferred leadership styles and two groups were identified. Some of the managers relied on both transformational behaviours and active transactional behaviours with an absence of behaviours associated with passive styles. The rest of the managers used behaviours associated with all the styles. An integrated personality profile was compiled for each manager. Definite trends were observed when comparing the profiles of the managers in the two leadership groups. Transformational leadership was defined in terms of the interpersonal more than the visionary aspect of leadership with interpersonal styles and work and social ethics being emphasised. Behaviours associated with transactional leadership as well as with more passive styles were also noted. The findings provide further support for the conceptualisation of leadership in terms of the full range model of leadership.

Keywords:16 PF; full range model; leadership; Multifactor Leadership Questionnaire; Occupational Personality Questionnaire; personality traits; Sixteen Personality Factor Questionnaire; transactional leadership; transformational leadership

The work environment is characterised by globalisation together with accelerating rates of change in markets, technologies, the work force, and work force expectations (Gordon Brown \& Bendixen, 2002; Horwitz, Kamoche, \& Chew, 2002; Van der Colff, 2003). Changes are taking place in cultural patterns, role definitions, structures, policies, procedures, and technologies (Krantz, 2001). Leader ship is central to this transformation and the full range model of leadership (with the transactional transformational distinction as basis) provides a framework for exploring the role of the leader in a changing work environment. According to Bass and Avolio (1994) transformational leadership provides an ideal of leadership, given contemporary developments in the global business world. Research supports the use of a transformational style given the rapidly changing technology (Howell \& Higgens, 1990), shift in work force expectations (Lowe, Kroeck, \& Sivasubramaniam, 1996; Sagie, 1997; Vroom, 2000), and need for doing business internationally and in multicultural envi ronments (Church \& Waclawski, 1999; Gibson \& Marcoulides, 1995; Rosenzweig, 1998).

The full range model is based on the concepts of transactional and transformational leadership 
as developed by Burns (1978 in Bass, 1997) and expanded by Bass (1985 in Bass, 1997). According to Bass (1997, p. 130) the transactional transformational distinction views leadership 'as either a matter of contingent reinforcement of followers by a transactional leader or the moving of followers beyond their self interests for the good of the group, organization, or society by a transformational leader'. The full range model in addition allows for passive behaviours and it can be regarded as a hybrid explanation (Bass, 1990; Den Hartog, Van Muijen, \& Koopman, 1997) incorporating aspects of various theoretical approaches. However, despite being a relatively comprehensive model, Yukl (1999) contends that some important leadership behaviours have been omitted and that this should be regarded as a weakness of a model referred to as the full range model of leadership.

The full range model includes laissez faire behaviour, transactional leadership, and transfor mational leadership (Bass \& Avolio, 1994). The conceptualisation of the leadership styles in the model is summarised in Table 1. These styles are regarded as separate dimensions and better leaders display each of the three styles to some degree. As mentioned the model represents various theoretical approaches but the conceptualisation of these leadership styles primarily in terms of the behaviours associated with each, links the model to trait theories. Trait theories focus on qualities that differentiate leaders from followers. The current perspective is that traits do not ensure leadership success but that some traits do distinguish effective leaders (Bateman \& Snell, 1999). In research as well as practice personality traits are usually operationalised in terms of behavioural preferences (or exposed personality traits). It should be noted that in the case of charisma, an essential transformational leadership behaviour (Carless, Wearing, \& Mann, 2000), the full range model distinguishes between charismatic behaviour and attributed charisma (Avolio, Bass, \& Jung, 1999; Conger \& Kanungo, 1994; Kanungo \& Conger, 1992).

Research on the personality traits associated with transactional and transformational leadership supports the conceptualisation of the leadership styles in terms of leadership behaviours and the nature of the influencing process, the latter consisting of a visionary and an interpersonal component. A focus on organisational change, a greater degree of risk taking, a tendency to be proactive, the use of more planning (futurity), and innovative problem solving characterise the transformational leader (Church \& Waclawski, 1998; Howell \& Higgens, 1990; Miller, Kets de Vries, \& Toulouse, 1982; Van Rensburg \& Crous, 2000). This corresponds with the definition of the transformational leader ${ }^{1}$ as being innovative and less likely to support the current situation, seeking opportunities in the face of risk, and attempting to shape and create rather than react to environmental circumstances (Lowe et al., 1996). However, Ross and Offermann (1997) did not find a need for change to be a significant predictor of transformational leadership. Interpersonal factors explained most of the variance in their study. Articulating a vision was found to be another distinguishing characteristic of transformational leadership, especially as a means for inspiring others (Church \& Waclawski, 1998; Hogan, 1994; Howell \& Higgens, 1990; Wofford, Goodwin, \& Whittington, 1998). The setting of long term goals reflects the need for achievement referred to by Howell and Higgens (1990) and Van Rensburg and Crous (2000).

Hogan (1994) emphasises social and interpersonal skills as present in transformational leaders. These skills are reflected in personality traits such as adjustment (e.g., being self confident and able to handle pressure), social impact (e.g., being outgoing and assertive), and agreeableness (e.g., being warm and friendly). Ross and Offermann (1997) found support for the presence of self confidence and Van Rensburg and Crous (2000) found that transformational leaders showed a need for affiliation and that their interpersonal relationships were warm, accepting, and supportive while they also showed an enjoyment of attention from others. Ross and Offermann (1997) found personality attributes associated with the functions of intellectual stimulation and individualised consideration to be the more consistent predictors of transformational leadership. A factor representing an enabling style of leadership characterised by practical support and concern for subordinate development explained most of the variance in their study. 
Table 1. Conceptualisation of the leadership styles in the full range model

\section{Transformational leadership}

Idealised influence implies that followers respect, admire, and trust the leader and emulate his or her behaviour, assume his or her values, and are committed to achieving his or her vision and making sacrifices in this regard. The leader shows dedication, a strong sense of purpose and perseverance, and confidence in the purpose and the actions of the group that helps to ensure the success of the group and gives followers a sense of empowerment and ownership. He or she behaves morally and ethically. Inspirational motivation refers to the leader(s enthusiasm and optimism in creating a vision of the future, thus stimulating similar feelings with followers. The leader is seen to commit to the vision, specific goals and expectations are clearly communicated, and confidence is expressed in followers' ability to achieve these expectations.

Intellectual stimulation implies a leader who values the intellectual ability of followers and who encourages innovation and develops creativity. Others are encouraged to reframe problems, use a holistic perspective in understanding problems, question the status quo, and approach problems from different angles, thus creating readiness for change and developing the ability to solve current and future problems.

Individualised consideration implies that the leader considers the ability of followers and their level of maturity to determine their need for further development. He or she acts as a mentor giving personal attention, listening to others' concerns, and providing feedback, advice, support, and encouragement. The leader furthermore designs appropriate strategies to develop individual followers to achieve higher levels of motivation, potential, and performance. Support is provided and progress monitored.

\section{Transactional leadership}

Transactional leadership involves a social exchange process where the leader clarifies what the followers need to do as their part of a transaction (successfully complete the task) to receive a reward or avoidance of punishment (satisfaction of the followers' needs) that is contingent on the fulfilment of the transaction (satisfying the leader's needs).

In the case of active management by exception, the leader looks for mistakes, irregularities, exceptions, deviations from standards, complaints, infractions of rules and regulations, and failures and he or she takes corrective action before or when these occur. Passive management by exception implies that the leader is reactive and waits to be informed about errors and deviances before taking action.

\section{Laissez-faire style or passive leadership}

This style implies avoidance or absence of leadership. The leader leaves responsibility for the work to followers and avoids setting goals and clarifying expectations, organising priorities, becoming involved when important issues arise, taking a stand on issues and making decisions. If this style is used as a component of other leadership styles it allows for the possibility of self management.

Based on Bass $(1990,1997)$ and Bass and Avolio $(1994,1995)$

The present discussion contributes to the personality leadership literature by using holistic profiles of individuals as the source of information rather than following the example of prior work and comparing groups that differ in leadership style in terms of their mean performance on separate personality traits. Mean scores could obscure the variation between members of a group as well as the preferences of the majority versus the exceptions. The same result on a specific trait, furthermore, has different interpretations depending on the way in which it is combined with other traits. In practice, the evaluation for placement and development of individuals in leadership positions includes an integrated personality profile that considers performance on all related traits. It was expected that the use of integrated profiles would add to the understanding of the full range model in terms of the personality traits associated with the leadership styles defined in this model. 


\section{METHOD}

An intervention was conducted at management level at one of the plants of a South African pro duction company that had been engaged in a process of transformation. In response to continuous changes in technology and customer demands, the organisation had been adapting at operational level and in terms of the composition and structuring of personnel. One of the aspects that had to be addressed was perceived differences in management styles between members of the management team and the impact thereof. Members of the management team were to be sensitised in terms of individual and group functioning, and assessment of and feedback on leadership styles and per sonality characteristics formed part of this process.

\section{Design}

The intervention focused on the above mentioned management team and questionnaires were administered to assess the leadership styles and personality traits of the members of the team. For each manager preferences in terms of leadership behaviours were identified and an integrated personality profile was drawn up. The intervention required individual feedback as well as feedback on the functioning of the group. It is the latter that forms the basis of the present discussion on the personality traits associated with different leadership styles. Although the use of the questionnaires imply numerical data and predetermined categories, this information was used to provide qualitative descriptions firstly at an individual and then at a group level. An integrated personality profile implies that performance on related traits is considered to describe functioning on a specific aspect (e.g., interpersonal confidence). The conclusion regarding such an aspect might be similar for indi viduals with different scores on the relevant traits. Trends, that would probably not have emerged in a quantitative analysis, can thus be identified at a group level. Based on leadership preferences the team could furthermore be divided into two groups. This made it possible to observe differences in personality between a group of more effective (or more transformational) managers and managers who could be regarded as less effective in terms of the leadership theory. Despite the small sample the qualitative nature of the interpretation made it possible to identify clear trends.

\section{Sample}

The management team consisted of a general manager, a technical expert, managers for the two phases of production, and managers for planning and logistics, quality control, engineering, human resources, finances, and marketing. Assessment results were available for eight of these managers. The members of the management team were primarily white, Afrikaans speaking males. Tenure varied, with some of them having been with the company only a few years and others for more than 10 years. Based on a confidentiality agreement, details of the primary task of the company and biographical information on individual respondents cannot be given. The holistic approach to inter pretation would only be possible with a small sample and the focus on the personality leadership relationship provides some justification for the relative homogeneity of the group in terms of demo graphic variables. Admittedly these aspects limit the generalisability of the findings.

\section{Measuring instruments}

The Multifactor Leadership Questionnaire Form 5X (MLQ 5X), the Occupational Personality Questionnaire version 32 (OPQ32), and the Sixteen Personality Factor Questionnaire, SA 1992 version (16PF, SA92) were used. The different versions of the latter questionnaires are regularly used for personality assessment in the South African context. The OPQ focuses on the workplace whereas the $16 \mathrm{PF}$ measures somewhat different traits in a number of contexts. The traits measured by these questionnaires correspond with those identified in earlier research on personality charac teristics associated with the leadership styles of the full range model. 
The MLQ 5X consists of 36 items that measure transformational leadership, transactional leadership, and laissez faire leadership (Bass \& Avolio, 1995). The remaining nine items measure outcomes of leadership. Each of the 45 items contributes to only one factor and the score for that factor is the average of the relevant items. Each manager completes a self assessment form on which he or she has to rate how often the leadership behaviour in each statement is practised on a range from 0 (not at all) to 4 (frequently, if not always). A rater form containing similar statements is completed by a superior, a peer, and subordinates indicating how often the behaviour is observed in the case of the manager. An effective leader is expected to obtain a rating of 3 (fairly often) on average for transformational leadership as well as on each of the five scales, a rating of 2 (some times) for contingent reward, between 1 (once in a while) and 2 (sometimes) for active management by exception, and between 0 (not at all) and 1 (once in a while) for passive management by exception and laissez faire behaviour. Support for the reliability and validity of the questionnaire has been based on a database consisting of 14 separate studies (Avolio et al., 1999). The Western capitalist culture of the management team included in the present study made the questionnaire suitable despite comparatively limited research in the South African context.

The OPQ32 is an updated version of the original OPQ Concept Model developed between 1981 and 1984 in the UK (SHL, 1999). The normative version used in this study consists of 230 state ments; respondents are asked to rate each statement on a scale ranging from strongly disagree (1) to strongly agree (5). Raw scores are transformed into scores on a sten scale for each of the 32 dimensions (the norms for a UK general population sample were used). The sten scores are interpreted in terms of the description on each bipolar scale of a low score, an average score, and a high score. The mean of 5.5 and standard deviation of 2 are considered in determining these categories. The 32 dimensions measured by the OPQ32 are grouped into four domains, namely, relationships with people, thinking style, feelings and emotions, and dynamism. A score on a Social Desirability scale is also obtained. Acceptable results in terms of the internal consistency reliability and the validity of the questionnaire is reported in the manual (SHL, 1999) and elsewhere (Barrett, Kline, Paltiel, \& Eysenck, 1996; Matthews \& Stanton, 1994; Robertson \& Kinder, 1993). Swane velder (2003) focused specifically on the usefulness of the questionnaire in the South African context and reports structural equivalence for black and white subgroups.

Prinsloo (1992) describes the development of the 16PF (SA92). The SA92 version consists of 160 items/questions; each item consists of a statement with three response options scored as 0,1 , or 2. The items are combined into 16 bipolar scales. Raw scores are transformed to a sten scale with a mean of 5.5 and a standard deviation of 2 . Norms are available for the total group and for males and females separately (the latter tables were used in this study). The sten scores are interpreted in terms of the description on each bipolar scale of a low score (range of 1 to 3), an average score (range of 4 to 7), and a high score (range of 8 to 10). The items are combined into 16 primary personality traits (Russell \& Karol, 1994) that in turn are combined in groups to obtain scores on the secondorder factors Extroversion, Anxiety, Emotional Sensitivity (Tough Poise), Independence, and Compulsivity (Prinsloo, 1992). A score is also obtained on the Motivational Distortion Scale (MD Scale). Reliability coefficients, the results of factor analyses, and subgroup comparisons are reported in the manual. According to Prinsloo (1992, p. 26) '... the questionnaire measures the same con structs, structured in the same way, in a reliable, valid and unbiased fashion among testees from any relevant subgroup'.

\section{Procedure}

The human resources manager arranged a session with the management team during which the rationale of the administration was explained and the personality questionnaires were completed. The manager who was qualified to do so conducted the administration. The leadership questionnaire 
implies self rating and ratings by others, and the questionnaires were distributed with instructions for completion to the relevant individuals. Paper and pencil versions of the questionnaires were used, and all the questionnaires were completed in English. The researcher provided guidelines for the human resources manager and also did the scoring and interpretation and gave individual and group feedback. Confidentiality was emphasised.

\section{Interpretation}

The members of the management team were evaluated in terms of their preferred leadership styles based on the ratings by others (superiors, peers, and subordinates). The average ratings for the managers in each of the groups are reported in Table 2. The four managers in the first group relied on both transformational and active transactional behaviours with an absence of behaviours associated with the passive styles. The average for transformational leadership as well as the ratings for four of the five scales (and the fifth in the case of two of the managers) indicated that they used the associated behaviours 'fairly often' (a rating of 3 ). All four managers used active transactional leadership (contingent reward and active management by exception) to the same extent as trans formational leadership. Passive management by exception and laissez faire leadership were used 'once in a while' or 'not at all' (ratings of 1 and 0 , respectively). This group would be referred to as the transformational group although it should be kept in mind that their reliance on active trans actional leadership is higher than expected for effective leadership. The four managers in the second group used behaviours associated with all the styles. With only a few exceptions, the ratings indi cated that they 'sometimes' (a rating of 2) used the various styles, implying most effective use only of active transactional leadership.

Table 2. Average ratings for the managers of the two groups

\begin{tabular}{|c|c|c|c|c|c|c|c|c|}
\hline \multirow[t]{2}{*}{ Leadership preferences } & \multicolumn{4}{|c|}{ Group 1} & \multicolumn{4}{|c|}{ Group 2} \\
\hline & 1 & 2 & 3 & 4 & 1 & 2 & 3 & 4 \\
\hline \multicolumn{9}{|l|}{ Transformational leadership } \\
\hline Idealised Attributes & $3 *$ & 3 & 3 & 3 & 2 & 2 & 2 & 2 \\
\hline Idealised Behaviours & 3 & 3 & 3 & 3 & 2 & 2 & 3 & 2 \\
\hline Inspirational Motivation & 3 & 3 & 3 & 3 & 3 & 2 & 3 & 3 \\
\hline Intellectual Stimulation & 3 & 3 & 3 & 3 & 2 & 2 & 2 & 2 \\
\hline Individualised Consideration & 2 & 2 & 3 & 3 & 2 & 2 & 2 & 2 \\
\hline Average & 3 & 3 & 3 & 3 & 2 & 2 & 2 & 2 \\
\hline \multicolumn{9}{|l|}{ Transactional leadership } \\
\hline Contingent reward & 2 & 3 & 3 & 3 & 2 & 2 & 3 & 2 \\
\hline $\begin{array}{l}\text { Management by exception } \\
\text { (active) }\end{array}$ & 3 & 3 & 3 & 2 & 2 & 2 & 2 & 2 \\
\hline $\begin{array}{l}\text { Management by exception } \\
\text { (passive) }\end{array}$ & 1 & 1 & 1 & 0 & 2 & 2 & 2 & 2 \\
\hline Laissez-faire & 1 & 1 & 0 & 1 & 2 & 1 & 2 & 2 \\
\hline
\end{tabular}

Note: * Average ratings have been rounded

Based on the OPQ and 16PF results, an integrated personality profile was developed for each of the managers. The manager was described in terms of the traits and behaviours associated with three broad categories, namely, thinking styles and problem solving patterns, general adjustment, and relationships and interpersonal styles. It is standard practice to use these categories in the interpretation of both the questionnaires. Trends in terms of the traits and behaviours in each of these categories were identified in each of the leadership groups and compared across the two groups. The 
criteria used were those identified in the section on the measuring instruments, and depending on low, average, or high scores as well as the combination of scores it was determined if the managers in a group showed patterns of behaviour (with or without exceptions) and how this compared across the two groups.

The first category deals with the individual's cognitive style and approaches to problem solving as well as the manner in which he or she deals with obligations. Conceptual thinking and creativity are evaluated together with the person's reality orientation, planning and organising abilities, and sense of responsibility. The OPQ dimensions associated with the domain of Thinking Style (grouped as analysis, creativity and change, and structure) are considered together with the 16PF primary factors that form part of the second order factors Tough Poise and Compulsivity as well as the primary factors Reasoning, Openness to Change, and Self reliance. Details on the scales associated with this category are presented in Table 3 .

Table 3. The OPQ and 16PF scales associated with thinking styles and problem solving patterns

\begin{tabular}{ll}
\hline \multicolumn{1}{c}{ OPQ } & \multicolumn{1}{c}{$\mathbf{1 6 P F}$} \\
\hline Thinking Style & Tough Poise \\
Analysis & Warmth \\
Data Rational & Sensitivity \\
Evaluative & Abstractedness \\
Behavioural & Compulsivity \\
Creativity and change & Rule consciousness \\
Conventional & Privateness \\
Conceptual & Perfectionism \\
Innovative & Other \\
Variety Seeking & Reasoning \\
Adaptable & Openness to Change \\
Structure & Self reliance \\
Forward Thinking & \\
Detail Conscious & \\
Conscientious & \\
Rule Following & \\
\hline
\end{tabular}

The second category deals with the individual's emotional adjustment and resilience as well as his or her energy and achievement orientation. Information based on the dimensions of the domain Feelings and Emotions (grouped as emotion and dynamism) are used together with the 16PF primary factors associated with the second order factor Anxiety. Detail on the scales associated with this category are presented in Table 4 .

The third category deals with the extent to which the individual enjoys social interaction and what role he or she plays in such interaction, how comfortable and competent he or she is in social situations, and the person's approach in terms of decision making and taking the lead. In the case of the OPQ the dimensions of the domain Relationships with People (grouped as influence, sociability, and empathy) and the dimensions Variety Seeking and Adaptable are considered. The latter is interpreted together with results on the 16PF second order factor Extraversion, the related primary factors, and the primary factors Vigilance and Privateness. Detail on the scales associated with this category are presented in Table 5 . 
Table 4. The OPQ and 16PF scales associated with general adjustment

\begin{tabular}{ll}
\hline \multicolumn{1}{c}{ OPQ } & \multicolumn{1}{c}{$\mathbf{1 6 P F}$} \\
\hline Feelings and Emotions & Anxiety \\
Emotion & Emotional Stability \\
Relaxed & Vigilance \\
Worrying & Apprehension \\
Tough Minded & Perfectionism \\
Optimistic & Tension \\
Trusting & \\
Emotionally Controlled & \\
Dynamism & \\
Vigorous & \\
Competitive & \\
Achieving & \\
Decisive & \\
\hline
\end{tabular}

Table 5. The OPQ and $16 \mathrm{PF}$ scales associated with relationships and interpersonal styles

\begin{tabular}{ll}
\hline \multicolumn{1}{c}{ OPQ } & \multicolumn{1}{c}{$\mathbf{1 6 P F}$} \\
\hline Relationships with People & Extraversion \\
Influence & Warmth \\
Persuasive & Dominance \\
Controlling & Liveliness \\
Outspoken & Social Boldness \\
Independent Minded & Self reliance \\
Sociability & Other \\
Outgoing & Vigilance \\
Affiliative & Privateness \\
Socially Confident & \\
Empathy & \\
Modest & \\
Democratic & \\
Caring & \\
Other & \\
Variety Seeking & \\
Adaptable & \\
\hline
\end{tabular}

\section{LEADERSHIP STYLES AND ASSOCIATED PERSONALITY TRAITS}

Expectations based on the conceptualisation of and research on the leadership styles as defined in the full range model are described. The trends identified in each group in the present study as well as the differences across the two groups are then presented.

\section{Thinking styles and problem-solving patterns}

Numerous authors refer to innovativeness and entrepreneurial qualities that lead to change, as per sonality characteristics of the effective leader (e.g. Bass, 1990; Bass \& Avolio, 1994, 1995; Church \& Waclawski, 1998; Hogan, 1994; Howell \& Higgens, 1990; Miller et al., 1982; Van Rensburg \& Crous, 2000; Wofford et al., 1998). Inspirational motivation implies a vision for the future that is 
different and challenging. This requires someone with a strategic approach and a willingness to experiment and implement change. A holistic perspective, an interest in conceptual thinking, a creative approach as well as a willingness to question assumptions, are also requirements for the function of intellectual stimulation (see Table 1).

It was expected that the above traits would be more prominent in the case of the transfor mational group in the present study. However, a clear distinction could not be made between the two groups in terms of conceptual and creative thinking. The results for the managers in both groups ranged from a focus on practical concerns to a high interest in conceptual thinking, innovation, and the critical evaluation of information.

Adherence to moral standards and rules furthermore reflects the ethical stance associated with a leader who exhibits idealised behaviour and also provides associates with values with which they can identify (Bass, 1990). A sense of responsibility also reflects the dedication that inspires asso ciates to share the leader's vision and goals. Clarity in terms of goals and the roles of associates in achieving them are requirements for both inspirational motivation and idealised behaviours. How ever, a preference for the structure provided by guidelines and adherence to regulations are also related to a contingent reward strategy and the use of active management by exception. Various authors (Bass, 1997; Hogan, 1994; Miller et al., 1982) refer to the transactional leader's focus on task performance and use of procedures to maintain control.

These patterns were observed in the present study and as this is one of the aspects where a clear distinction could be made between the two groups, detail is provided in Tables 6 and 7 to illustrate the interpretation process. With one exception, the managers exercising a transformational style indicated adherence to moral standards and rules and a sense of responsibility in both work and social contexts. All the managers in this group furthermore showed adherence to regulations in the work context implying a degree of rigidity. These traits reflected the managers' reliance on both transformational and active transactional behaviours. The managers in the second group either showed concern for moral standards and rules or strict adherence to regulations in a work context, but did not indicate a consistent profile of commitment to social as well as work related obligations. This reflected the active transactional style of this group combined with aspects of the passive styles such as talking about getting work done but not always taking responsibility.

\section{General adjustment}

Resilience in terms of self confidence, self determination, a lack of internal conflicts, and the ability to handle pressure underlie the idealised influence practiced by the transformational leader (Bass, 1990; Hogan, 1994; Ross \& Offermann, 1997). The effective leader (who primarily relies on transformational behaviour and only uses the other styles when appropriate) is furthermore focused on achievement (Van Rensburg \& Crous, 2000) and dedication, inner direction, and a high activity and energy level contribute to the leader's function as role model. Enthusiasm and optimism are also required to create a vision of the future and effective problem solving requires self confidence.

Although a clear distinction between the two groups in terms of general adjustment was not possible, the trends support the expectations in terms of leadership styles. The managers in both groups seemed to be resilient, although some apprehension and emotional reactiveness were noted. A degree of complacency was observed in the case of the second group (the managers who did not show a preference in terms of leadership style). The managers in both groups furthermore seemed ambitious, with more moderate levels of energy and drive indicated in the case of the second group. The more placid, less active profile seen for this group probably reflects times when these managers used a style of taking action only when things go wrong and being absent and not taking responsi bility for setting goals and making decisions. 
Table 6. The interpretation process in terms of social and work related obligations (group 1)

\begin{tabular}{lcccc}
\hline Personality traits & Manager 1 & Manager 2 & Manager 3 & Manager 4 \\
16PF: Rule consciousness & 8 & 9 & 7 & 4 \\
16PF: Perfectionism & 8 & 7 & 7 & 6 \\
OPQ: Conscientious & 8 & 4 & 9 & 4 \\
OPQ: Rule Following & 8 & 8 & 7 & 7
\end{tabular}

\section{Interpretation for manager 1}

The manager is disciplined and ordered and he would strive to behave in a considerate and socially precise manner. He is furthermore a responsible and persevering person who needs to see tasks through to completion. (He probably expects the same from others.) Together with the adherence to standards and regulations this might indicate some lack of flexibility (but a high degree of reliability where deadlines and prescribed work methods are set down).

\section{Interpretation for manager 2}

The manager tends to be self disciplined and organised and he would make an effort to behave in a considerate and socially acceptable manner. He is a responsible and persevering person who could be somewhat rigid in conforming to standards and rules. He prefers the structure provided by clear guidelines and this adherence to regulations could at times be at the cost of completing a task or meeting deadlines.

\section{Interpretation for manager 3}

The manager tends to be self disciplined and seems to conform to what is generally regarded as acceptable behaviour and to show regard for moral standards and rules. He is a conscientious and persevering person with a strong emphasis on task completion and meeting deadlines. Also in a work context does he show a preference for some structure in the form of guidelines.

\section{Interpretation for manager 4}

The manager seems reasonably self disciplined and aware of and willing to adhere to what is regarded as socially approved behaviour. Nevertheless, in both a social and a work context some flexibility with regard to obligations is observed. In the latter context he shows some preference for structure and a tendency to follow rules and regulations.

\section{Trends observed for the group*}

With one exception, the managers exercising a transformational style indicated adherence to moral standards and rules and a sense of responsibility in both work and social contexts. All the managers in this group furthermore showed adherence to regulations in the work context implying a degree of rigidity. These traits reflected the managers' reliance on both transformational and active transactional behaviours.

Note: $*$ The scores on the personality traits were used to formulate the individual interpretations. Trends were based primarily on these integrated interpretations that provide more information than the scores on the specific traits or averages for traits or a combination of traits.

\section{Relationships and interpersonal styles}

According to Bass (1990), charismatic leaders have a need to influence others. This, however, is coupled with sensitivity to follower's needs. Social impact involves confidence and assertiveness in social situations (Hogan, 1994; Ross \& Offermann, 1997). Idealised influence implies that the leader has to provide clear direction for the group and show confidence in their purpose and actions. One expects the leader to be willing to influence others either through taking control and providing direction or through negotiation and persuasion. Idealised influence, inspirational motivation, and intellectual stimulation furthermore require an assertive and outspoken leader who voices his values and beliefs, clearly states his vision, questions assumptions, and challenges associates in terms of their performance and development. These functions of transformational leadership, however, also 
Table 7. The interpretation process in terms of social and work related obligations (group 2)

\begin{tabular}{lcccc}
\hline Personality traits & Manager 1 & Manager 2 & Manager 3 & Manager 4 \\
16PF: Rule consciousness & 9 & 5 & 4 & 8 \\
16PF: Perfectionism & 9 & 7 & 6 & 6 \\
OPQ: Conscientious & 6 & 6 & 5 & 3 \\
OPQ: Rule Following & 6 & 8 & 8 & 4
\end{tabular}

\section{Interpretation for manager 1}

The manager is perfectionistic and would conform to what is regarded as socially approved behaviour with (rigid?) adherence to moral standards and rules. High expectations would also be set for others. However, in a work context task deadlines and rules and procedures would be approached with more flexibility (average scores were obtained).

\section{Interpretation for manager 2}

The manager tends to be disciplined and he would make an effort to behave in a socially approved manner. He indicates reasonable responsibility in terms of social and work related obligations and in the latter context he would emphasise adherence to rules and procedures.

\section{Interpretation for manager 3}

The manager is reasonably self disciplined and aware of what is regarded as socially acceptable. However, he tends to be less conforming in terms of social standards and this could to some extent affect the way in which he regards his obligations in this context. He indicates moderate concern for task completion and he would in a work context adhere to regulations and procedures.

\section{Interpretation for manager 4}

The manager indicates reasonable self discipline and regard for what is seen as socially acceptable behaviour. He furthermore takes his social responsibilities seriously and would adhere to moral standards. Somewhat conflicting with this he tends to be less restricted by regulations in the workplace and he is flexible in terms of task completion and meeting deadlines.

\section{Trends observed for the group*}

The managers in the second group either showed concern for moral standards and rules or strict adherence to regulations in a work context, but did not indicate a consistent profile of commitment to social as well as work related obligations. This reflected the active transactional style of this group combined with aspects of the passive styles such as talking about getting work done but not always taking responsibility.

Note: * The scores on the personality traits were used to formulate the individual interpretations. Trends were based primarily on these integrated interpretations that provide more information than the scores on the specific traits or averages for traits or a combination of traits.

require consultation with and active participation by associates. They need to feel a sense of em powerment and ownership (idealised influence), goals need to be in alignment with their own needs (inspirational motivation), and their intellectual ability needs to be valued and their creativity developed (intellectual stimulation).

The managers exercising a transformational style scored average to high in terms of the traits associated with influencing others and taking the lead. With one exception, these managers also indicated that they were open to suggestions, involved others in decision making, and were inclined to go with the majority decision. The managers in the other group indicated assertiveness and a willingness to express themselves, and they scored average to high in terms of their willingness to influence others. However, only one of the managers in this group involved associates, while the others showed self interest and valued their own intellect more than that of their followers reflecting a directive transactional approach or the passive styles at times practiced by these managers. 
Murphy and Ensher (1999) discuss the concept of a continuum of leader member roles which reflects the extent to which the leader treats followers as in or out group members. The relationship with the in group members is based on transformational behaviours, with the leader showing a need for affiliation and being warm, accepting, and supportive in his or her interpersonal relationships (Liden \& Maslyn, 1998; Ross \& Offermann, 1997; Van Rensburg \& Crous, 2000). According to Bass (1990), the charismatic leader inspires trust, confidence, acceptance, obedience, and affection from followers. Identification and trust and inspiring and stimulating others imply active partici pation by the leader. Individualised consideration, however, provides the means for moving from transactional to transformational leadership (Avolio \& Bass, 1995). This requires concern for subordinate development at an individual level. The relationship with out group members is based on the contract characterising the transactional style.

The manager who preferred to make his own decisions also seemed more reserved, but the other managers in the transformational group indicated that they were outgoing, enjoyed the company of others, and were active in their interactions. All of them indicated trust in and tolerance towards others and were at least reasonably caring and supportive towards and concerned about others (average to high scores). However, being objective individuals implied greater task orientation than people orientation. This made sense in terms of their use of active transactional behaviour where the interaction with associates is aimed at the delegation of tasks rather than individual issues or problems. The managers in the second group mostly indicated that they were reserved and impersonal although they were at least reasonably responsive in their interactions (with the manager who involves others in decision making being more extroverted but with a tendency to be wary of others). They were furthermore mostly selective with their support and preferred to remain detached from others' problems. This non involvement is a feature of the passive styles.

\section{CONCLUSIONS}

The findings of the present study largely supported the conceptualisation of leadership styles in terms of the full range model of leadership. The leadership styles practised were associated with persona lity traits and behaviours relevant to the descriptions of these styles. In summary, the managers who used a transformational style indicated personality traits associated with this type of leadership. Average to high scores in terms of strategic thinking, a conceptual and innovative approach, and critical evaluation of information were coupled with moral concerns, a sense of responsibility, and perseverance. These managers also showed at least reasonable resilience as well as ambition and motivation. Regarding the interpersonal aspect of leadership, this group indicated assertiveness and a need to influence others while also allowing participation by associates and involving others in decision making. These managers were characterised by a need for affiliation, responsiveness in interaction, trust in and tolerance towards others as well as being reasonably caring. The manifes tation of these traits, however, was influenced by their use of transactional leadership. They seemed more task oriented than people oriented, and their need for structure probably also affected the inspirational aspect of leadership. One of the managers in this group did not in all aspects fit the above profile and his personality characteristics corresponded to some extent with that of the second group. Although the people who rated him observed much of his behaviour as transformational, this was not always supported in terms of the expected personality traits. For fear of over interpretation only a tentative explanation is provided, namely, that his lower post level implied raters at a lower post level who might have evaluated leadership behaviour differently.

Because the managers in the other group used a transformational style at times, the associated traits were also to some extent observed in that group. Traits and behaviours associated with trans actional leadership as well as with the more passive styles were, however, also noted. The managers in this group seemed to be task oriented and probably practiced a more directive rather than partici 
pative transactional style. Passive behaviours included a placid attitude, fluctuation in commitment, and a lack of involvement with others. Also in this group the profile of one of the managers varied from the above. This can be explained in terms of his emphasis on certain transactional and passive behaviours despite an overall transformational profile.

Interpersonal styles and work and social ethics distinguished the managers practising transfor mational leadership and it was therefore mainly the traits and behaviours associated with idealised influence and individualised consideration that characterised this leadership style the inter personal more than the visionary aspect of leadership. This distinction has been related to iden tification with the person versus identification with goals. The findings provide valuable guidelines on determining the profile of the effective leader, but also partly indicate perceived effectiveness rather than an objective evaluation. The leader is evaluated by others and it is possible that these raters associated effective leadership with social values and interpersonal satisfaction. The managers in this study furthermore emphasised transactional behaviours in terms of their need for structure and their focus on task performance. This is probably not only necessary (given the manufacturing environment) but also effective and shows the need for contextual considerations in applying a theory or model.

The small sample size and the very specific nature of the management team and of the company imply that the generalisability of the results is limited. However, these factors made it possible to use an approach that highlighted trends in the personality leadership relationship that would probably have been obscured in a quantitative study. As seen in the literature a quantitative replication of the study with a more representative sample would nevertheless add to the information in this field. It is conceded that the greatest value of the approach used is in terms of the description of the functioning of a specific group thus contributing to any intervention done at this level.

\section{NOTE}

1. 'Transformational leader' refers to a leader relying primarily on transformational behaviours with appro priate use of the behaviours associated with the other styles.

\section{REFERENCES}

Avolio, B. J., \& Bass, B. M. (1995). Individual consideration viewed at multiple levels of analysis: A multi level framework for examining the diffusion of transformational leadership. Leadership Quarterly, 6, 199218.

Avolio, B. J., Bass, B. M., \& Jung, D. I. (1999). Re examining the components of transformational and transactional leadership using the Multifactor Leadership Questionnaire. Journal of Occupational and Organizational Psychology, 72, 441462.

Barrett, P., Kline, P., Paltiel, L., \& Eysenck, H. J. (1996). An evaluation of the psychometric properties of the concept 5.2 Occupational Personality Questionnaire. Journal of Occupational and Organizational Psychology, 69, 119.

Bass, B. M. (1990). Bass and Stogdill's handbook of leadership: Theory, research, and managerial applications (3rd edn.). New York: The Free Press/Macmillan.

Bass, B. M. (1997). Does the transactional transformational leadership paradigm transcend organizational and national boundaries? American Psychologist, 52, 130139.

Bass, B. M., \& Avolio, B. J. (1994). Introduction. In B. M. Bass \& B. J. Avolio (eds.), Improving organizational effectiveness (pp. 1 9). Thousand Oaks, CA: Sage.

Bass, B. M., \& Avolio, B. J. (1995). Multifactor Leadership Questionnaire Report. Palo Alto, CA: Mind Garden.

Bateman, T. S., \& Snell, S. A. (1999). Management: Building competitive advantage (4th edn.). Boston: Irwin/McGraw Hill.

Carless, S. A., Wearing, A. J., \& Mann, L. (2000). A short measure of transformational leadership. Journal of Business and Psychology, 14, 389405. 
Church, A. H., \& Waclawski, J. (1998). The relationship between individual personality orientation and executive leadership behaviour. Journal of Occupational and Organizational Psychology, 71, 99125.

Church, A. H., \& Waclawski, J. (1999). The impact of leadership style on global management practices. Journal of Applied Social Psychology, 29, 14161443.

Conger, J. A., \& Kanungo, R. N. (1994). Charismatic leadership in organizations: Perceived behavioral attributes and their measurement. Journal of Organizational Behavior, 15, 439452.

Den Hartog, D. N., Van Muijen, J. J., \& Koopman, P. L. (1997). Transactional versus transformational leadership: An analysis of the MLQ. Journal of Occupational and Organizational Psychology, 70, 1934.

Gibson, C. B., \& Marcoulides, G. A. (1995). The invariance of leadership styles across four countries. Journal of Managerial Issues, VII, 176192.

Gordon Brown, C., \& Bendixen, M. (2002). Grant Thornton Feinstein Pretoria: A winning culture? (Report WBS 2002 2). Johannesburg: Wits Business School.

Hogan, R. (1994). Trouble at the top: Causes and consequences of managerial incompetence. Consulting Psychology Journal, 46, 915.

Horwitz, F. M., Kamoche, K., \& Chew, I. K. H. (2002). Looking East: Diffusing high performance work practices in the southern Afro Asian context. The International Journal of Human Resource Management, 13, 10191041.

Howell, J. M., \& Higgens, C. A. (1990). Champions of technological innovation. Administrative Science Quarterly, 35, 317341.

Kanungo, R. N., \& Conger, J. A. (1992). Charisma: Exploring new dimensions of leadership behavior. Psychology and Developing Societies, 4, 2138.

Krantz, J. (2001). Dilemmas of organizational change: A systems psychodynamic perspective. In L. J. Gould, L. F. Stapley, \& M. Stein (eds.), The systems psychodynamics of organizations: Integrating the group relations approach, psychoanalytic, and open systems perspectives (pp. 133 156). London: Karnac.

Liden, R. C., \& Maslyn, J. M. (1998). Multidimensionality of leader member exchange: An empirical assessment through scale development. Journal of Management, 24, 4372.

Lowe, K. B., Kroeck, K. G., \& Sivasubramaniam, N. (1996). Effectiveness correlates of transformational and transactional leadership: A meta analytic review of the MLQ literature. Leadership Quarterly, 7, 385425.

Matthews, G., \& Stanton, N. (1994). Item and scale factor analyses of the Occupational Personality Questionnaire. Personality and Individual Differences, 16, 733743.

Miller, D., Kets de Vries, M. F. R., \& Toulouse, J. (1982). Top executive locus of control and its relationship to strategy making, structure, and environment. Academy of Management Journal, 25, 237253.

Murphy, S. E., \& Ensher, E. A. (1999). The effects of leader and subordinate characteristics in the development of leader member exchange quality. Journal of Applied Social Psychology, 29, 13711394.

Prinsloo, C. H. (1992). Manual for the use of the Sixteen Personality Factor Questionnaire, South African 1992 version (16PF, SA92). Pretoria: Human Sciences Research Council.

Robertson, I. T., \& Kinder. A. (1993). Personality and job competences: An examination of the criterion related validity of some personality variables. Journal of Occupational and Organizational Psychology, 65, 225244.

Rosenzweig, P. (1998). Managing the new global workforce: Fostering diversity, forging consistency. European Management Journal, 16, 644652.

Ross, S. M., \& Offermann, L. R. (1997). Transformational leaders: Measurement of personality attributes and work group performance. Personality and Social Psychology Bulletin, 23, 10781086.

Russell, M. T., \& Karol, D. L. (1994). The 16PF fifth edition administrator's manual. Champaign, IL: Institute for Personality and Ability Testing.

SHL. (1999). OPQ32 manual and user's guide. Surrey, SHL Group plc. 
Sagie, A. (1997). Leader direction and employee participation in decision making: Contradictory or compatible practices? Applied Psychology: An International Review, 46, 387452.

Swanevelder, C. (2003). The construct equivalence of the OPQ32n for Black and White subgroups in South Africa. Paper presented at the 6th Annual Industrial Psychology Conference, Johannesburg, South Africa.

Van der Colff, L. (2003). Leadership lessons from the African tree. Management Decision, 41, 257261.

Van Rensburg, C., \& Crous, F. (2000). Die verband tussen sekere persoonlikheidseienskappe en transformasionele leierskap (The relationship between certain personality traits and transformational leadership). Journal of Industrial Psychology, 26, 3946.

Vroom, V. H. (2000). Leadership and the decision making process. Organizational Dynamics, 28, 8294.

Wofford, J. C., Goodwin, V. L., \& Whittington, J. L. (1998). A field study of a cognitive approach to understanding transformational and transactional leadership. Leadership Quarterly, 9, 5584.

Yukl, G. (1999). An evaluation of conceptual weaknesses in transformational and charismatic leadership theories. Leadership Quarterly, 10, 285305. 